\title{
Inaplicabilidade do artigo 66 do Código de Defesa do Consumidor - indicativos para adoção do direito administrativo sancionador
}

\author{
Alexandre Rodeguer Baggio ${ }^{1}$ \\ Prof. Ms. Marcos Daniel Veltrini Ticianelli ${ }^{2}$
}

\begin{abstract}
Resumo
0 presente trabalho visa demonstrar que o artigo 66 inserido no Código de Defesa do Consumidor não tem o alcance necessário para determinar uma efetiva punição ao agente causador do dano. Desta forma, o Direito Penal fica adstrito a um valor simbólico dentro da relação de consumo, causando assim, uma insegurança jurídica. Será verificado o abuso à não observância do Princípio da Intervenção M ínima, que causa um desgaste desnecessário ao Direito Penal que deveria se interpor como ultima ratio. Visto que, não há o cuidado técnico de observação principalmente da dignidade penal e da carência da tutela penal, é que se indaga sobre a implantação do Direito Administrativo Sancionador como meio de solução da problemática.
\end{abstract}

Palavras-Chave: Consumidor; Simbolismo penal; Sanção penal; Sanção administrativa.

\section{Introdução}

O Código de Defesa do Consumidor trouxe um entendimento totalmente novo sobre as relações de consumo, mesmo e tão somente depois de uma década e meia de aplicação pode-se argumentar que os inúmeros princípios norteadores nele inseridos necessitam de muita indagação, para finalmente, assumir uma forma definitiva de proteção ao consumidor.

Neste aspecto, o valor simbólico que o Direito Penal está vivendo em sua aplicação no Código de Defesa do Consumidor, será verificado principalmente na inaplicabilidade do artigo 66 do CDC, tomado como exemplo no presente trabalho, pois quem sofre a sanção deste artigo, acaba por sentir apenas um valor metafórico, e que não cria o temor que se esperava ao longo dos anos de cumprimento do Código, causando desta forma uma

\footnotetext{
${ }^{1}$ Bacharel em Direito pela UNOPAR - Universidade Norte do Paraná; Especialista em Direito e Processo Penal pela UEL - Universidade Estadual de Londrina; Professor do Curso de Direito do ICES - Instituto Catuaí de Ensino Superior de Cambé; Membro participante do Projeto de Pesquisa "Estado e Relações Empresariais: Diálogos Filosóficos e Jurídicos diante da Regulação Estatal sobre a Ordem Econômica Nacional" do Departamento de Direito Público da UEL - Universidade Estadual de Londrina.

2 Professor orientador do presente Artigo Científico apresentado ao Curso de Pós-graduação Lato Sensu em Direito e Processo Penal, da Universidade Estadual de Londrina.
} 
insegurança jurídica, quando deveria impor uma base sólida de atuação nas relações de consumo.

Após a Revolução Industrial na Europa (1750) é que a idéia de consumo e proteção ao consumidor começa a ser formada, mesmo que a curtíssimos passos. A cadeia de eventos que concebe e envolve a complexa relação de consumo, absorvem os conceitos já existentes referentes à produção intelectual, valores éticos, valores normativos, fenômenos sócioeconômicos, formação cultural e religiosa, comportamento social de massa e outros.

A industrialização dos produtos e as linhas de montagem deram início às fabricações em série e a padronização dos gostos. Cada nação, cada povo, há seu tempo e conforme sua cultura vai lapidando a concepção de relação de consumo e consumidor, até que surge a proteção a estes.

Nos dias atuais as diretrizes das relações de consumo procuram ainda estabelecer quais os conceitos e os princípios que devem ser adotados e seguidos, qual o bem jurídico penalmente tutelado que foi atingido.

A dedução acima se faz necessária de plano, porque em termos de geopolítica e avanço da globalização, as tendências de marketing de consumo oferecerão ao consumidor um poder de controle incomensurável sobre os produtos oferecidos. Dessa forma o efeito de cognição sumária entre oferta e procura, relações de consumo e suas conseqüências para 0 indivíduo e para a sociedade devem ter uma rápida resposta quanto aos preceitos violados.

Tal avanço é tão sério e real que para o Congresso Americano em 2006 foram eleitos em peso os Deputados do Partido Democrata que fizeram suas campanhas com a idéia central de atuação baseadas no protecionismo defendendo uma antiglobalização. A abordagem desse tema é essencial porque os Estados Unidos da América tem por idealismo o livre comércio ditando as normas da economia mundial onde estão inseridas as relações de consumo.

A União Européia busca um fortalecimento através da formação de blocos econômicos para se manter habilitada na escalada do consumo mundial, tornando-se viável quanto ao oferecimento dos seus produtos.

É neste cenário globalizado que o Brasil se encontra, com um avançado Código de Defesa do Consumidor, porém, que ainda necessita buscar uma agilidade na esfera jurídica, principalmente a criminal, para que possa responder à altura do crescimento do mercado, 
tendo que enfrentar fortes empresas estrangeiras com sólida formação de mercado, como por exemplo, Microsoft, AT\&T, Apple, IBM, Oracle, Google, YouTube, BankBoston, Santander, HSBC, Johnson \& Johnson, Procter \& Gamble, Carrefour, Wal-M art, Volkswagen, BMW, Renault-Nissan, Toyota, M ercedes Bens, Duke Energy, as Empresas de Telefonia, etc.

0 presente estudo tem o objetivo de buscar compreender através de uma análise estrutural de aplicação da Lei no. 8.078/90 e seus resultados, verificando os Direitos dos consumidores e os Princípios das relações de consumo inseridos no texto Constitucional, influência dos tipos penais na sociedade, principalmente a verificação da inaplicabilidade do artigo 66 do Código de Defesa do Consumidor.

Portanto, visando atingir um resultado melhor, sem inflacionar o Direito Penal tendo que perturbá-lo a todo o momento, é que estudaremos os indicativos para adoção do Direito Administrativo Sancionador.

\section{Direitos do consumidor e Constituição Federal de 1988}

A Constituição Federal no artigo 5ํㅡㄹ inciso XXXII ${ }^{3}$, e artigo 170, inciso $\mathrm{V}^{4}$, e no Ato das Disposições Constitucionais Transitórias no artigo $48^{5}$, mostra explicitamente que já havia a clara intenção de Proteção ao Consumidor.

A proteção mencionada fica marcada pela vulnerabilidade do consumidor na relação jurídica de consumo (NUNES, 2006, p. 125). Essa hipossuficiência faz com que o consumidor tenha o total esclarecimento quanto ao produto adquirido bem como garantias legais de ter seu direito reconhecido de forma ágil para que não seja lesado duas vezes, uma na relação de consumo e outra na busca de seus direitos.

A fixação legal da norma jurídica se dá pela solidez de sua aplicação, portanto, proteção ao consumidor é o esforço para o progresso da norma jurídica, é o cuidado que se toma em relação aos interesses alheios (DINIZ, 1998, p. 829).

Os Princípios Constitucionais de proteção e de defesa ao consumidor outorgam ao Estado a função de tutelar as diretrizes que organizam os interesses desse consumidor.

Assim, os princípios mais detidamente transformam-se em Direitos do Consumidor, estão inseridos mais especificamente, nos Direitos Coletivos. Estes, só podem ser exercidos comunitariamente, por conta da existência de um vínculo jurídico que surge da união de pessoas em determinado grupo.

\footnotetext{
${ }^{3}$ BRASIL. Constituição Federal. São Paulo. Revista dos Tribunais. 2007.

${ }^{4}$ Id. Ibid

${ }^{5}$ Id. Ibid.
} 
Formado o grupo, e estabelecido o direito coletivo, esta reunião fica estabelecida como uma proteção dos direitos fundamentais do cidadão-membro de uma coletividade, isso de certa forma contraria a princípio, os direitos individuais, os seja, do cidadãoindivíduo.

Porém, não é dessa forma que ocorre, pois sendo garantido o direito coletivo, muito mais forte se torna o direito individual, sendo que, 0 alicerce formado nesta relação serve para dar base aos direitos fundamentais tanto individuais quanto coletivos.

Nestes termos, observa-se que o direito do consumidor pertence à categoria dos direitos fundamentais de natureza coletiva (PASSARELLI, 2002, p. 13). Como os direitos e garantias do consumidor podem ser lesados ora de forma individual, ora de forma coletiva, é verificada a impossibilidade de supressão do dispositivo legal, por extensão, baseado no artigo 60, parágrafo 40 da Constituição Federal (BRASIL, CF, 2007). Tornando assim, muito mais robusta a discussão em tela, pois não poderá ser objeto de deliberação qualquer proposta de emenda constitucional que tenha intenção de abolir os direitos e garantias do consumidor.

Inegável a contundente proteção que a Constituição Federal fornece ao consumidor. Resta saber sobre a efetiva necessidade da aplicação do Direito Penal nesta seara, visto que, com a referida proteção estabelecida, parte da doutrina discorda da tutela penal nos bens coletivos, como assevera o Professor de Direito da Universidade de Coimbra Dr. Manuel da Costa Andrade. Para o festejado Professor o Direito Penal deve atuar como ultima ratio, devendo ser observada a "dignidade penal (juízo qualificado de intolerabilidade social) e a carência de tutela penal" (COSTA ANDRADE, 2004, p. 278-289), como será observado a seguir.

\section{Princípios penais e suas influências nas relações de consumo}

Para que se entenda a correlação entre os princípios nas relações de consumo e suas influências nas infrações penais faz-se mister examinar o que a doutrina esclarece sobre os princípios.

Conforme o renomado autor Celso Antônio Bandeira de Mello (1992, p. 299), os princípios: 
São mandamentos nucleares de um sistema, verdadeiro alicerce dele, disposição fundamental que se irradia sobre diferentes normas, compondo-lhes o espírito e servindo de critério para sua exata compreensão e inteligência, exatamente por definir a lógica e a racionalidade do sistema normativo, no que lhe confere tônica e Ihe dá sentido harmônico. É o conhecimento dos princípios que preside a intelecção das diferentes partes componentes do todo unitário que há por nome sistema jurídico positivo.

Ainda nesta seara Maria Helena Diniz (1998, p. 717) acompanhando Leibniz, Descartes, Newton e Spencer indaga que princípios:

São cada uma das proposições diretivas ou características a que se subordina 0 desenvolvimento de uma ciência, e que são regras fundamentais de qualquer ciência ou arte.

Na concepção de Carlos Ari Sundfeld (1992, p. 137), princípios são:

as idéias centrais de um sistema, ao qual dão sentido lógico, harmonioso, racional, permitindo a compreensão de seu modo de organizar-se.

Portanto, é importante identificar que o princípio de proteção ao consumidor trazido pela Lei no. 8.078/90, elenca o consumidor a categoria de sujeito hipossuficiente nas relações de consumo, isso é demonstrado claramente nos artigos 42 caput e 47 que visam o interesse na proteção deste sujeito menos privilegiado no exercício de defesa de seus direitos.

Necessária é a leitura dos artigos 42 caput e 47 do Código de Defesa do Consumidor:

Art. 42 caput - "Na cobrança de débitos, o consumidor inadimplente não será exposto ao ridículo, nem será submetido a qualquer tipo de constrangimento ou ameaça".

Art. 47 - As cláusulas contratuais serão interpretadas de maneira mais favorável ao consumidor".(BRASIL,1999)

Fica evidenciado através dos artigos supra que o Código busca cercar o consumidor atribuindo a este uma couraça protetiva, sendo que, tais preceitos são embasados nas concepções principiológicas que se verificou anteriormente. A partir dessa conclusão, formada através de um nexo entre princípios, relação de consumo e consumidor é que o 
Código foi além, buscando inserir no contexto legal, tipificações penais para certos comportamentos das partes que são economicamente fortes na relação de consumo.

Visto isso, verificaremos os artigos 66 caput, 67 e 69 do Código de Defesa do Consumidor e a alusão entre estas tipificações penais e os princípios que as embasaram, e ainda uma análise sobre a possibilidade de um Direito Administrativo Sancionador.

Senão vejamos abaixo, respectivamente 0 artigo 66 nos remete aos princípios da veracidade e da transparência, 0 artigo 67 que denota o princípio da publicidade e 0 artigo 69 que está em consonância ao princípio da verdade que informa a publicidade, conforme faz referência o ilustre autor M arcos Daniel Veltrini Ticianelli (2005).

Art. 66 caput - "Fazer afirmação falsa ou enganosa, ou omitir informaç̧ão relevante sobre a natureza, característica, qualidade, quantidade, segurança, desempenho, durabilidade, preço ou garantia de produtos ou serviços".

Art. 67 - "Fazer ou promover publicidade que sabe ou deveria saber ser enganosa ou abusiva".

Art. 69 - "Deixar de organizar dados fáticos, técnicos e científicos que dão base à publicidade". ${ }^{6}$

Conforme o renomado autor M arcos D. V. Ticianelli que cita em sua dissertação de mestrado em Direito 0 artigo 66 do Código, trazendo uma discussão doutrinária sobre sua índole publicitária.

0 mesmo autor expõe dois posicionamentos da doutrina, o primeiro no sentido de que não há intervenção da atividade publicitária no tipo penal que tutela o direito de informação verdadeira, com base nos posicionamentos de Luiz Regis Prado, Paulo José da Costa Júnior, João Batista de Almeida, Domingos Afonso Kriger Filho, Antonio César de Lima Fonseca e Antonio Herman Benjamim, e, o segundo posicionamento é no sentido de que 0 artigo 66 também representa a atividade publicitária, com base nos posicionamentos de Maurício Zanoide de Moraes e Luiz Luisi (TICIANELLI, 2005, p. 75-76).

Segundo o nobre autor Nelson Nery Júnior (2002, p. 30) houve punição pelo artigo 66 da veiculação da publicidade falsa, pois esclarece 0 autor que, "a publicidade pode ser

\footnotetext{
${ }^{6}$ BRASIL. Lei 8.078 , de 11 de setembro de 1999. Dispõe sobre a proteção do consumidor e dá outras providências. Diário Oficial da União 12.09.1990.
} 
verdadeira, mas, ainda assim pode ser considerada enganosa, se omitir algum dado essencial para aquele anúncio publicitário".

Porém, 0 artigo 66 do Código será mais detidamente verificado no capítulo seguinte.

Passemos então ao artigo 67 do Código que foi objeto de um profundo estudo na dissertação de mestrado em Direito do Professor Marcos D. V. Ticianelli.

Como relata o ilustre autor à publicidade é um fenômeno intrínseco à sociedade de consumo, e é benéfica a este. Se porventura ocorrer da conduta publicitária ser considerada enganosa ou abusiva, esta será extremamente prejudicial ao contexto econômico e social. Nestes termos, faz-se necessária à tutela do Direito Penal intervindo na proteção dos direitos e interesses do consumidor (TICIANELLI, 2005, p. 78).

Neste mesmo aspecto Nelson Nery Júnior comenta que o legislador penal foi bem rigoroso no artigo 67 do Código, pois o texto legal oferece punição ao fornecedor que sabia do caráter enganoso da publicidade ou que devia saber dessa característica (NERY JúNIOR, 2002, p. 30).

Para finalizarmos este capítulo que teve por missão trazer alguns princípios polêmicos no que tange a necessidade de intervenção penal no Código de Defesa do Consumidor, faremos por fim uma breve análise do artigo 69 do Código.

Antonio Herman Benjamin citado por Marcos D. V. Ticianelli (2005, p. 137) nos ensina que, "a regra é de que o fornecedor só deve informar aquilo que sabe e que pode provar".

Esclarece ainda o Professor Ticianelli que conforme Antonio Cézar Lima da Fonseca, "não se verifica delito na questão direta e efetiva proteção dos mencionados valores que retratam o bem jurídico. Isto porque o preceito administrativo que origina e fundamenta a tutela penal nada mais é do que a representação de uma função administrativa, cujo objetivo e razão de existir é a conexão do fornecedor com o legítimo interessado" (FONSECA, 2005, P. 139).

Para Nelson Nery Júnior (2002, p. 31) o artigo 69 de Código constitui prática de crime. Para o nobre autor "a conduta criminosa tipificada é a consistente na omissão, por parte do fornecedor, em organizar dados fáticos, técnicos e científicos que dêem base à publicidade. Mesmo sendo verdadeira e não abusiva a propaganda, na hipótese de 0 
fornecedor não possuir arquivados os dados comprobatórios da alegação publicitária, configurada estará a prática de crime".

Como vimos, somente estes três artigos do Código de Defesa do Consumidor já trazem uma polêmica digna de estudos mais profundos e mantém aberta a discussão sobre a dicotomia de aplicação do sistema de Direito Penal do Consumidor ou do Direito Administrativo Sancionador.

\section{Inaplicabilidade do artigo 66 do código de defesa do consumidor}

A análise pretendida neste capítulo ficará limitada a inaplicabilidade do artigo 66 do Código de Defesa do Consumidor, e como, se dará a criação do vínculo através da pena aplicada e a efetividade da punição, demonstrando uma pretensa eficácia para a sociedade que espera uma resposta à altura do potencial incutido no Direito Penal como meio de defesa de seus direitos.

Portanto é inevitável a indagação neste capítulo sobre a tímida atuação do artigo 66 do CDC. Através de uma pena simplória este artigo não oferece segurança jurídica, e fica impedido pelo Princípio da Especialidade a utilizar-se do artigo 299 do Código Penal. Este com uma pena proporcionalmente maior ofereceria uma melhor eficácia, pois a similaridade entre as áreas de atuação dos dois artigos é bem próxima, porém, prevalece o Princípio da Especialidade ao artigo 66 do CDC.

Para facilitar a análise, vejamos os dois artigos e suas penas:

Art. 66 CDC - "Fazer afirmação falsa ou enganosa, ou omitir informação relevante sobre a natureza, característica, qualidade, quantidade, segurança, desempenho, durabilidade, preço ou garantia de produtos ou serviços":

Pena - detenção de 03 (três) meses a 1 (um) ano e multa.

$\S 10$ Incorrerá nas mesmas penas quem patrocinar a oferta.

$\S 2$ o Se o crime é culposo:

Pena - detenção de 1 (um) a 6 (seis) meses e multa" ${ }^{7}$

Art. 299 CP - "Omitir, em documento público ou particular, declaração que dele devia constar, ou nele inserir ou fazer inserir declaração falsa ou diversa da que

\footnotetext{
${ }^{7}$ BRASIL. Lei 8.078 , de 11 de setembro de 1999. Dispõe sobre a proteção do consumidor e dá outras providências. Diário Oficial da União 12.09.1990.
} 
devia ser escrita, com o fim de prejudicar direito, criar obrigação ou alterar a verdade sobre fato juridicamente relevante:

Pena - reclusão, de 1 (um) a 5 (cinco) anos e multa, se o documento é público, e reclusão de 1 (um) a 3 (três) anos, e multa, se o documento é particular". ${ }^{8}$

Observar-se-á, portanto que em ambos os artigos no contexto de uma relação de consumo o bem jurídico ofendido é Princípio da Informação e da Transparência.

Conforme pode nos esclarecer M aria Helena Diniz (1998, p. 723):

Princípio da Informação - (Direito do Consumidor). "Aquele que requer que 0 consumidor receba informação clara, precisa e verdadeira sobre os produtos e serviços fornecidos, baseando-se na boa-fé e na lealdade".

Princípio da Transparência - (Direito do Consumidor). "É aquele pelo qual a atividade e a mensagem publicitárias devem assegurar ao consumidor informações claras, corretas e precisas" (DINIZ, 1998, p. 732).

O Professor Marcos D. V. Ticianelli $(2005$, p. 71) ponderou de forma bem específica à questão da informação verídica, completa, transparente e exata. E assevera que, "a criminalização das condutas publicitárias, objetivam inibir a publicidade prejudicial ao sistema econômico, às relações de consumo e, por fim, ao próprio consumidor que tem o direito a uma informação adequada aos preceitos legais".

Resta por óbvio que no caput do artigo 66 do CDC quando se verifica as características, a qualidade, a quantidade, a segurança, o desempenho, a durabilidade ou garantia de produtos ou serviços, torna-se impossível pelos consumidores uma compreensão razoável do que é o produto ou o serviço, se esta compreensão não vier através da publicidade que lhe chama a atenção para o produto ou o serviço.

Como bem nos informa o ilustre Professor Marcos D. V. Ticianelli $(2005$, p. 78), “a publicidade atua como um fenômeno intrínseco à sociedade de consumo, e é benéfica ao consumidor. Porém, se a conduta publicitária for considerada enganosa e abusiva ela tornase extremamente prejudicial ao contexto econômico e social, e sugere, portanto a necessidade de intervenção penal.

Visto isso, para entendermos este vínculo entre um artigo e outro é necessário que, se verifique que a interpretação aqui é axiológica, pois a falsidade publicitária visa incutir valores à sociedade de consumo ou manipulá-los de forma comercial.

${ }^{8}$ BRASIL. Código Penal. São Paulo. Revista dos Tribunais. 2007. 


\section{Inaplicabilidade do artigo 66 do Código de Defesa do Consumidor: indicativos para adoção do direito administrativo sancionador}

A ilustre autora M aria Helena Diniz (1998, p. 752) esclarece que:

O conceito axiológico que tem por objeto os próprios valores, atuando no sentido de função seletiva do valor, sendo utilizada para valorar outros valores. A ideologia possui um papel neutralizador do valor. A valoração ideológica é uma metacomunicação que estima as estimativas, valora as próprias valorações, seleciona as seleções ao dizer ao endereçado como este deve vê-las. A ideologia atua como um elemento estabilizador, valorando os próprios valores, organizandoos possibilitando sua sistematização. Com a ideologia, o valor subjetivo passa a ser objetivo, correspondendo ao valor vigente e predominante na sociedade atual, positivado pela ordem jurídica. (negrito nosso)

Ainda, utilizando-se das anotações da ilustre autora:

Documento falso é aquele que não corresponde, total ou parcialmente, à realidade dos fatos (DINIZ, 1998, p. 861).

Publicidade é qualquer forma de divulgação de mensagens, por meio de anúncio, para influenciar o consumidor a adquirir produtos ou usar serviços.

Publicidade comercial é 0 ato ou processo que visa despertar o interesse do consumidor para o produto ou serviço divulgado por meio de anúncios, prospectos, cartazes, boletins, etc. (DINIZ, 1998, p. 862).

Observemos um julgado do Superior Tribunal de Justiça:

“Na falsidade documental, ganha corpo à simulação. A matéria encerra negócio jurídico inexistente no todo ou em parte. Na falsidade ideológica sobressai a fraude. 0 agente omite ou introduz declarações no documento, que não deveria expressar. Aqui o negócio jurídico existe, todavia, formalmente, projetado de modo diferente". DJU de 23/03/1992, p. 3.491 (MIRABETE, 2000, p. 1.623). (negrito nosso)

Voltemos mais uma vez às anotações de Maria Helena Diniz, que nos esclarece sobre a fraude principalmente a fraude penal:

(negrito nosso)

Fraude Penal - (Direito Penal). Ato de má-fé que venha a lesar a outrem, afetando a sociedade (DINIZ, 1998, p. 599). (negrito nosso)

Dentro dos aspectos anteriormente citados, não se pode deixar de relacionar 0 caráter da especialidade referente ao artigo 299 do Código Penal em relação ao artigo 66 do Código de Defesa do Consumidor. 
Não se trata de uma interpretação puramente gramatical e isolada pinçando as palavras dos dois artigos, como por exemplo, [...] afirmação falsa ou enganosa [...] (artigo 66 CDC), [...] declaração que dele devia constar ou nele inserir ou fazer inserir declaração falsa ou diversa [...] (artigo 299 CP), ou ainda, [...] omitir informação relevante [...] (artigo 66 CDC), [...] omitir, em documento público ou particular [...] (artigo 299 CP).

Indaga-se, o caráter do artigo 299 do Código Penal, deve ficar inoperante frente ao Princípio da Especialidade, ou o seu potencial punitivo deveria ser aplicado para que houvesse uma efetiva aplicação do artigo 66 nas relações de consumo, para que dessa forma este mantivesse o status de um Direito Penal punitivo e eficaz, que traz uma reposta à sociedade que faz desse direito sua esperança de Justiça.

Ante 0 exposto, chega-se a um dos pontos cruciais que fazem referência ao trabalho aqui apresentado. As discussões na esfera penal são aguerridas, porém, o consumidor vê a cada situação, seu real direito a uma resposta rápida e eficaz se perder no tempo dentro dos Tribunais.

Insólito o consumidor perde a voz, e desfalece com o tempo que leva seu direito para longe de seu alcance. A ferocidade com que o mercado trabalha, a informação cotidiana que se torna massacrante, a publicidade diuturna apaga o rastro do crime cometido, ainda assim, sem medo daquela punição que mesmo vindo tardia é apenas simbólica.

\section{Efetivo alcance da lei №. 8.078/90: sanção penal ou sanção administrativa}

Como foi visto no capítulo anterior não é difícil criar polêmicas sobre os tipos penais inseridos no Código de Defesa do Consumidor.

Porém, façamos uma análise racional. A quem interessa um direito penal do consumidor nos moldes em que hoje ele se apresenta, ou seja, ineficiente?

A utilização do direito penal nas relações de consumo não nasceu da Lei no. 8.078/90. No Código Penal de 1940 já havia tipos penais que incriminavam certas situações no comércio. Ainda, após o Código Penal, surgiram as Leis no. 1.521/51 da Economia Popular e a Lei no. 7.492/86 do Sistema Financeiro Nacional, que já levavam as relações de consumo pelo caminho do direito penal. 
Tal situação só vem demonstrar que o legislador brasileiro é despreparado, e que segue as opiniões do momento, tornando patente à inaplicabilidade dos tipos penais no Código de Defesa do Consumidor.

Como bem assevera o ilustre autor Eduardo Reale Ferrari não há previsão legislativa para condutas de perigo abstrato, "tornando dessa forma vulneráveis as garantias do direito penal moderno, constituindo a presunção de prova inadmissível em contrário, atingindo não somente o princípio da culpabilidade, mas a própria presunção de inocência" (FERRARI, 2004, p. 277).

Ainda, indica o ilustre autor que, "a única forma de minimizar esta afronta cometida pela legislação penal consumerista é entender que os crimes previstos no Código de Defesa do Consumidor e em outras Leis penais devem ser sempre de perigo concreto, ou seja, afrontam bem jurídico determinado e específico, pois não sendo desta forma, haverá um empobrecimento dos pressupostos de punibilidade" (FERRARI, 2004, p. 277). Esta falta de efetividade na punição causa descrédito ao direito penal e cria um ambiente que serve de avanço nas condutas infracionais.

Para que houvesse uma verdadeira efetividade do Direito Penal nas relações de consumo, a formulação dos tipos penais inerentes a estas relações, deveriam observar a Dignidade Penal (COSTA ANDRADE apud FERRARI, 2004, p. 278) diante das relações sociais que porventura causassem uma grave lesão ao bem jurídico penalmente tutelado, e, a Carência de Tutela Penal que somente deveria ocorrer quando determinada sanção administrativa não alcançasse o resultado pretendido, colocando em ação o Direito Penal como ultima ratio.

Como bem assevera o renomado Professor Dr. Manuel da Costa Andrade (apud FERRARI, 2004, p. 278), da Faculdade de Direito da Universidade de Coimbra, Portugal, "o legislador brasileiro exagera ao primar pela tutela penal sobre bens coletivos".

Essa afirmação do nobre Professor Dr. Manuel surge de forma muito lúcida no que diz respeito à visão do Direito Penal contemporâneo.

O Direito Penal não deve jamais perder sua natureza de proteção também ao consumidor. Em respeito ao próprio ser humano o Direito Penal deve seguir sempre uma linha de raciocínio onde, a exigência da tutela penal sobre determinado bem jurídico deve 
ser eficaz a ponto de atingir sempre a natureza do crime, proporcionando uma justa punição equivalente ao crime cometido.

A ineficiência cotidiana na contenção das infrações penais nas relações de consumo demonstra a falta de Dignidade Penal que denotam alguns tipos penais previstos no Código de Defesa do Consumidor, como por exemplo, o artigo 66, que conforme já citado no capítulo anterior põe em dúvida a sua própria atuação, levando ainda ao questionamento do artigo citado sobre a Carência de Proteção Penal.

Tendo visto as considerações acima, é importante investigarmos o Princípio da Intervenção M ínima, conforme segue:

Princípio da Intervenção Mínima do Direito Penal - (Direito Processual Penal e Direito Penal. "É aquele em que o Direito Penal só é aplicado em casos de ataque aos bens jurídicos mais importantes (Muñoz Conde). É uma limitação ao exercício da atividade penal, como modo de resolução dos conflitos. Aquele pelo qual o direito deve abster-se de intervir em certas situações, protegendo apenas bens indispensáveis ao desenvolvimento humano em comunidade e atuando subsidiariamente, quando outras medidas de controle social fracassarem (Alberto Z. Toron) (DINIZ, 1998, p. 724)".

Através do Princípio da Intervenção Mínima o legislador brasileiro deveria ficar impedido de criminalizar condutas irrelevantes e por via de conseqüência impor sanções desnecessárias, em contribuição a formulação legislativa deve ser verificada a impossibilidade de limitação à restrição à liberdade que não por meio do Direito Penal, e ainda, este princípio delimita a criação do tipo penal sujeitando-o a necessidade e carência de sua formulação.

Corroborando o entendimento verificado, denota o ilustre Professor Dr. Luiz Regis Prado sobre o Princípio da Intervenção M ínima:

0 princípio da intervenção mínima ou da subsidiariedade estabelece que o Direito Penal só deve atuar na defesa dos bens jurídicos imprescindíveis à coexistência pacífica dos homens e que não podem ser eficazmente protegidos de forma menos gravosa. Desse modo, a lei penal só deverá intervir quando for absolutamente necessário para a sobrevivência da comunidade, como ultima ratio. $E$, de preferência, só deverá fazê-lo na medida que for capaz de ter eficácia. Aparece ele como uma orientação político-criminal restritiva do jus puniendi e deriva da própria natureza do Direito Penal e da concepção material de Estado de Direito democrático. 0 uso excessivo da sanção criminal (inflação penal) não garante uma maior proteção de bens; ao contrário, condena o sistema penal a uma função meramente simbólica e negativa. (PRADO, 2005, p.149)(negrito nosso) 
Visto isso, a posição mais lógica conforme emanada no presente estudo é de Gunter Heine, que apresenta três possibilidades de atuação, relacionando a sanção penal e a sanção administrativa.

A primeira é a de dependência total entre os sistemas penal e administrativo, a segunda elege um direito penal relativamente dependente da administração, e a terceira proposta é a de independência total entre as instâncias (HEINE apud FERRARI, 2004, p. 289290).

A segunda proposta também denominada de funcionamento alternativo é a que parece fornecer um posicionamento mais acertado, pois prioriza a atuação e 0 sancionamento na seara administrativa, socorrendo-se do Direito Penal em casos de extrema necessidade.

Tal posicionamento é corroborado por Hassemer e seguidores da escola de Frankfurt, que pregam a não ingerência penal quando possível à atuação do Direito Administrativo Sancionador.

Os órgãos destinados a gerir esse sistema híbrido devem ter poderes sólidos de sancionamento, com garantias de independência e estabilidade, a exemplo hoje das Agências Reguladoras.

E, em contrapartida, mesmo sendo estas questões no âmbito de sanções administrativas, devem ser plenamente observadas as garantias fundamentais do devido processo legal, do contraditório e da ampla defesa, e a fundamentação das decisões.

\section{Conclusão}

Diante das polêmicas levantadas e as análises realizadas, não há a presunção de esgotar em absoluto este assunto que surge ainda como hipóteses a serem aplicadas.

Porém, à primeira vista é notório que o delinqüente econômico não é passível de reinserção, reeducação e reabilitação social. Há uma conotação totalmente diferenciada das "infrações penais" nas relações de consumo com os delitos previstos no Código Penal como meio de tutela do Estado, como já se apresenta no ordenamento jurídico vigente.

Não se pode infantilizar o status sócio-intelectual e a sofisticação do modus operandi desse delinqüente inserto nas relações de consumo, a saber, grandes empresas e marcas, e renomados empresários que, com o desgastado discurso de criação e manutenção 
de empregos, auferem isenções de impostos, fazem reserva de mercado, padronizam preços desestabilizando a base da concorrência e vilipendiam os consumidores, pois tem a certeza da falta de alcance do Direito Penal do consumidor e sua inaplicabilidade sancionatória.

Surge portanto, a via do Direito Administrativo Sancionador, que irá tratar as relações de consumo de forma diferente de como trata o Direito Penal, este que busca regrar o homo medius, que não é o perfil do agente que delinqüe nas relações de consumo.

Cabe-nos agora, a defesa de um sistema administrativo sancionatório, que vise atender o consumidor hipossuficiente, tratando-o de forma equânime.

\section{Referências}

AM ARAL, Sylvio do. Falsidade documental. 4. ed. Campinas/SP: M illennium, 2000.

BAUM, William M. Compreender o Behaviorismo: ciência, comportamento e cultura. Porto Alegre: Artmed, 1999.

BLANCHET, Luiz Alberto. Curso de Direito Administrativo. 5. ed. Curitiba: Juruá, 2006.

BRASIL. Código Civil, Código de Processo Civil, Constituição Federal. Organizador Yussef Said Cahali. 9. ed. São Paulo: Revista dos Tribunais, 2007.

. Código Penal, Código de Processo Penal, Constituição Federal. Organizador Luiz Flávio Gomes. 9. ed. São Paulo: Revista dos Tribunais, 2007.

. Lei 8.078, de 11 de setembro de 1999. Dispõe sobre a proteção do consumidor e dá outras providências. Diário Oficial da União 12.09.1990.

DINIZ, M aria Helena. Dicionário Jurídico. São Paulo: Saraiva, 1998. v. 1-4.

FERNANDES, Antonio Scarance. Processo Penal Constitucional. 2. ed. São Paulo: RT, 2000.

FERRARI, Eduardo Reale. Direito Penal do Consumidor e Constituição Federal Brasileira. Ciências Penais. Revista da Associação Brasileira de Professores de Ciências Penais, São Paulo, v. 1, n. 1, p. 274-294, jul./ dez. 2004.

GOLEM AN, Daniel. Inteligência Emocional. 16. ed. Rio de Janeiro: Objetiva, 1995.

IHERING, Rudolf von. A Luta pelo Direito. São Paulo: Martin Claret, 2006. JÚNIOR, José Júlio Lozano. Prescrição Penal. São Paulo: Saraiva, 2002.

MELLO, Celso Antônio Bandeira de. Elementos de direito administrativo. São Paulo. Malheiros. 1992. 
MEZZAROBA, Orides; M ONTEIRO, Cláudia Servilha. Manual de M etodologia da Pesquisa no Direito. 2. ed. São Paulo: Saraiva, 2005.

M IRABETE, Julio Fabrini. Código Penal Interpretado. São Paulo: Saraiva, 2000.

NUNES, Rizzatto. Curso de Direito do Consumidor. 2. ed. São Paulo: Saraiva, 2005.

PASSARELLI, Eliana. Dos Crimes contra as Relações de Consumo. São Paulo: Saraiva, 2002.

PRAD0, Luiz Régis. Curso de Direito Penal Brasileiro. 5. ed. São Paulo: RT, 2005. v. 1. Parte Geral.

SKINNER, B. F. Ciência do Comportamento Humano. São Paulo: M artins Fontes, 1990.

SUNDFELD, Carlos Ari. Fundamentos de direito público. São Paulo: M alheiros, 1992.

TICIANELLI, Marcos Daniel Veltrini. Alguns Aspectos do Controle Penal da Publicidade no Código de Defesa do Consumidor e na Lei 8.137/90. 2005. Dissertação (M estrado em Direito Penal) - Universidade Estadual de M aringá, M aringá, 2005.

TRÊS, Celso Antônio. Teoria Geral do Delito pelo Colarinho Branco. Curitiba: Imprensa Oficial do Estado do Paraná, 2006. 